\title{
Features and problems of metrological traceability of gas mixtures using UV absorption, FTIR, and CRD spectroscopy
}

\author{
Leonid Konopelko ${ }^{1,2}$, Vitaly Beloborodov ${ }^{1,2}$, Ian Chubchenko ${ }^{1}$, and Dmitry Rumiantsev ${ }^{1}$ \\ ${ }^{1}$ D. I. Mendeleyev Institute for Metrology (VNIIM), Saint Petersburg, Russia \\ ${ }^{2}$ University of Information Technologies, Mechanics and Optics (ITMO), Saint Petersburg, Russia
}

\begin{abstract}
Metrological traceability is usually realized by comparing the high precision gas mixtures (reference standards (RS)) and working standards used for calibration of gas analyzers. The procedures with the use of UV absorption, FTIR, and CRD spectroscopy for the transfer of the mole fraction from the RS to the working standards are developed, in order to reduce the required number of RS and improve the accuracy of measurements. For the successful use of existing spectroscopic databases, the most accurate data was necessary to identify and attribute the uncertainty, based on our own experimental work carried out using the RS. Further on the transfer of the mole fraction from the RS to the working standards can be done without the use of the RS. In the case of CRDS, when the matrix of the studied gas mixture is different from air, the broadening of the spectral lines associated with the interactions between molecules leads to significant error in the measurement of concentration of the studied gas. The effects leveling benefits of the CRDS method are studied.
\end{abstract}

\section{Introduction}

At present in Russia about thirty factories manufacture working standards of gas mixtures in total quantity over 70,000 cylinders a year.

Many efforts have to be completed to ensure the traceability of measurement by achieving metrological traceability from the Primary Measurement Standard of Mole Fraction and Mass Concentration of Components in Gas Media (GET 154-2011) [1] to working standards used for calibration of gas analyzers. Metrological traceability is usually realized by comparing the high precision gas mixtures (reference standards (RS)) and working standards. The number of required RS in Russia is about 1,000 gas mixtures in cylinders annually, which is a serious burden for the GET 154-2011.

The first aim of this work was to develop measurement methods to minimize the quantity of RS i.e. primary reference gas mixtures (PRGM) used for the units transference from the GET 154-2011 [1] to working standards. The second aim of this work was to increase the accuracy of transference of a mole fraction from the GET 154-2011 to working standards. These aims were completed by the use of UV absorption, FTIR, and CRD spectroscopy. GET 154-2011 is a complex of installations that serves for the production of PRGM and transfer of units to working standards.

\section{Features and problems}

Modern optical instrumentation working in wide spectral regions or in narrow spectral bands and using special computer programs can potentially measure gas concentrations with high precision. However, the development backlog of spectral methods from the measurement capabilities of modern instrumentation leads to loose accuracy and to complications in analyses.

Spectral absorption measurement methods of substance concentrations are based on comparisons of measured spectrum and reference spectrum. We explore in this work the method of receiving the reference spectrum which is based on spectrum computation with the use of known the spectroscopic parameters of molecules and the spectral characteristics of the instrumentation. Among the available spectroscopic databases used for math spectra modeling, at present, the most widely used are the HITRAN [2] and GEISA [3] databases. There are also catalogs of cross-sections of a large number of substances, e.g., the MPI-Mainz-UV-VIS Spectral Atlas [4] and the NIST Standard Reference Database 79 [5].

All the above-mentioned spectroscopic databases and catalogs are not metrologically ensured. This is one reason why modern spectral optical methods have not been implemented in a gas analysis in full.

Two requirements are needed to measure gas concentrations precisely with the use of computed spectra as follows:

1. Precise knowledge of the spectral line parameters. Computed spectra can differ from the measured spectra taken for the same gas concentration because of the inaccuracy of spectral line parameters.

2. Precise knowledge of the instrument function and other technical data of the spectrophotometer.

The D. I. Mendeleyev Institute for Metrology (VNIIM) participated in international key comparisons CCQM-P110-B2 [6] conducted under the aegis of the International Bureau of Weights and Measures (BIPM) to solve these two issues. Methods and measurement procedures were developed to transfer units from GET 154-2011 to working standards.

Scientific basis and methods of practical implementation are surveyed in this work.

The procedure [7] provides a certification of two components CSs in cylinders under pressure with the use of the UV spectroscopy. 
The procedure makes a provision for measurements of mole fraction in gas mixtures by the UV spectroscopy at the given wavelength and given spectral resolution conducted on the Cary 5000 spectrophotometer which is included in a UV-IR spectrometric installation of the GET 154-2011.

According to the procedure gas mixture from a cylinder under pressure is forwarded in a gas cell installed in a spectrophotometer and the transmission $\mathrm{T}$ is measured.

The shape of calibration curve has been chosen on basis of analysis of dependence of optical density of investigated gas mixture on concentration at the chosen wavelengths and chosen spectral resolutions using measured spectra of PRGM.

\section{Table 1. Accuracy figures of the measurement procedure.}

\begin{tabular}{|l|l|l|}
\hline $\begin{array}{l}\text { Target } \\
\text { component } \\
\text { and matrix* }\end{array}$ & $\begin{array}{l}\text { Measurement range } \\
\text { of mole fraction of } \\
\text { target component in gas mixture, \% }\end{array}$ & $\begin{array}{l}\text { The relative expanded uncertainty of measurement, } \\
U^{0}, \% \\
\text { for coverage factor } k=2 * *\end{array}$ \\
\hline $\mathrm{NO}+\mathrm{N}_{2}$ & from 0.0050 up till 3.0 & 1.1 \\
\hline $\mathrm{Cl}_{2}+\mathrm{N}_{2}$ & from 0.05 up till 10 & 0.8 \\
\hline
\end{tabular}

Footnote:

* Target component and matrix are indicated correspondently.

** Corresponds to confidence interval of the relative expanded uncertainty of measurement (for a level of confidence

$P=0,95)$.

Another procedure was developed for measuring the mole fraction of the components $(\mathrm{HCl}, \mathrm{CO}, \mathrm{NO}, \mathrm{SO} 2)$ in twocomponent gas mixtures in cylinders under pressure by IR spectroscopy [8]. This procedure is also used to transfer units from the GET 154-2011 to working standards.

The gas mixture from the cylinder under pressure is blown into a gas cell installed in the sample compartment of the FTIR spectrometer for registration of transmittance spectrum in the spectral range $400-4000 \mathrm{~cm}^{-1}$. With the help of the developed software "SpectraLab 2.0" the obtained transmission spectrum is compared to the estimated transmittance spectrum, formed on the basis of the spectroscopic database HITRAN or GEISA in the specified conditions of measurement (the value of the molar fraction of the analyte obtained according to the preparation procedure, atmospheric pressure, temperature, optical path length of the cuvette, the instrument function), and the molar fraction of the analyte is calculated. The value obtained is corrected using the correction factor $\mathrm{K}$, taking into account the systematic shift of measurement results for the optical train.

Correction factors representing the ratio of the molar fraction of the analyte given in the passport of a gas mixture in a cylinder to the concentrations computed using the HITRAN or GEISA database were established using PRGMs by infrared FTIR spectrometer FSM 1201.

Table 2. Correction factors.

\begin{tabular}{|l|l|l|}
\hline $\begin{array}{l}\text { Composition of gas } \\
\text { mixture }\end{array}$ & $\begin{array}{l}\text { Range of mole fraction of measured } \\
\text { component in gas mixture, \% }\end{array}$ & Correction factor K \\
\hline $\mathrm{HCl}+\mathrm{N}_{2}$ & from 0.10 up till 0.30 & 1,054 \\
\hline $\mathrm{CO}+\mathrm{N}_{2}$ & from 0.1 up till 8.0 & 1,050 \\
\hline $\mathrm{NO}+\mathrm{N}_{2}$ & from 0.2 up till 5.0 & 1,056 \\
\hline $\mathrm{SO}_{2}+\mathrm{N}_{2}$ & from 0.05 up till 7.5 & 1,036 \\
\hline
\end{tabular}

It was substantiated on basis of investigations that optimal algorithm of spectra handling is algorithm with the use of the synthetic spectrum and the special spectroscopic database. Such database includes spectral lines parameters, integral absorption coefficients, adjustment coefficients etc. Also an instrument line shape should be controlled with the use of test gas mixture (CO in nitrogen).

Adoption of modern FTIR and development of new method of measurement ensures remote units transfer from GET 154-2011 to manufactured gas mixtures based on methods of IR absorption spectroscopy. This goal is of great practical importance especially for countries with large territory when manufacture of PRGMs and measurement means are exceedingly geographically distributed.

Wavelength-scanned cavity ring-down spectroscopy (WS CRDS) is also used in gas analysis. Test gas mixtures containing carbon monoxide, carbon-12 dioxide, carbon-13 dioxide, methane, and formaldehyde are used to determine the metrological characteristics of WS CRDS gas analyzers. Most experimental results are in agreement with the declared data. For gas mixtures in which the gas matrix differs from air, the broadening of spectral lines related to the interaction of particles causes significant errors in the concentration measurements. Such effects that neutralize the advantages of the WS CRDS method were studied [9]. The coefficients that can be used to correct the results of the WS CRDS gas analyzers and compensate for errors related to different gas matrices are found. 
The theoretical estimations were followed by a practical study of the effect of gas matrix on the results of the WS CRDS gas analysis. To estimate the effect of the gas matrix on measured quantities $\mathrm{xCO}_{2}, \mathrm{xCH}_{4}, \mathrm{xCO}$, we studied more than 30 samples with different $\mathrm{CH}_{4}, \mathrm{CO}$, and $\mathrm{CO}_{2}$ contents. Parameters $\mathrm{xCH}_{2} \mathrm{O}$ (nitrogen), $\mathrm{xCH}_{2} \mathrm{O}(\operatorname{argon})$, and $\mathrm{xCH} \mathrm{H}_{2} \mathrm{O}$ (air) were obtained in the experiments with gas mixtures of formaldehyde with air, nitrogen, and argon that are produced by the generator of gas mixtures. For each mixture, the correction coefficient was calculated. The random error was then determined. The measured results for gas mixtures with identical concentrations of the gas under study and different gas matrices differ by ratio $\mathrm{k}$.

Table 3. Results of the WS CRDS gas analysis for the gas mixtures containing $\mathrm{CH}_{4}, \mathrm{CO}, \mathrm{CO}_{2}$, $\mathrm{CH}_{2} \mathrm{O}$, and different gas matrices.

\begin{tabular}{|l|l|l|l|}
\hline & Ratio $(\mathrm{k})$ & Error $(\Delta \mathrm{k})$ & Ratio of [10] \\
\hline $\mathrm{xCO}_{2}$ (азот) $/ \mathrm{xCO}_{2}$ (воздух $)$ & 0.97 & 0.01 & 0.976 \\
\hline $\mathrm{xCO}($ азот $) / \mathrm{xCO}$ (воздух $)$ & 0.92 & 0.03 & \\
\hline $\mathrm{xCH}_{4}($ азот $) / \mathrm{xCH}_{4}($ воздух $)$ & 0.990 & 0.005 & 0.994 \\
\hline $\mathrm{xCH}_{2} \mathrm{O}($ азот $) / \mathrm{xCH}_{2} \mathrm{O}$ (воздух $)$ & 0.92 & 0.03 & \\
\hline $\mathrm{xCH}_{2} \mathrm{O}($ аргон $) / \mathrm{xCH}_{2} \mathrm{O}$ (воздух) & 1.57 & 0.03 & \\
\hline
\end{tabular}

\section{Conclusion}

Both aims, i.e. to develop measurement methods to minimize the quantity of PRGMs and to increase the accuracy of transference of a mole fraction from the GET 154-2011 to working standards were completed in the series of works. Adoption of modern instrumentation and development of new methods of measurement will ensure a remote units transfer from the GET 154-2011 [1] to manufactured gas mixtures based on methods of spectroscopy.

\section{References}

1. GOST 8.578 - 2008. State system for ensuring the uniformity of measurements. State verification scheme for measuring instruments of the content of components in gaseous media.

ГОСТ 8.578-2008 Государственная система обеспечения единства измерений (ГСИ). Государственная поверочная схема для средств измерений содержания компонентов в газовых средах. (in Russian).

2. L.S. Rothman et al. The HITRAN2012 molecular spectroscopic database. JQSRT 130 (2013) 4-50.

3. N. Jacquinet-Husson at al. The 2009 edition of the GEISA spectroscopic database. JQSRT 112 (2011) $2395-2445$.

4. MPI-Mainz-UV-VIS Spectral Atlas: http://joseba.mpch-mainz.mpg.de/spectral_atlas

5. NIST Standard Reference Database 79: http://www.nist.gov/srd/nist79.cfm

6. Edgar Flores et al. Final report on Pilot Study CCQM-P110: Study on the accuracy and uncertainty of FT-IR methods calibrated with synthetic spectra for $\mathrm{NO}_{2}$ concentration measurements. Metrologia 50 (2013), Tech. Suppl., $08011 ; 97$ pages.

7. L.Konopelko, V.Beloborodov, D.Rumiantsev and D.Selukov. Perfecting methods of metrological traceability of priority air pollutants using UV absorption spectroscopy. International Congress of Metrology, 21-24 September, 2015. Paris. Page68. http://cfmetrologie.edpsciences.org/articles/metrology/pdf/2015/01/metrology metr2015 07006.pdf

8. L.Konopelko, V.Beloborodov, D.Rumiantsev and D.Selukov. Development of gases mole fraction and concentration transference procedures with the use of Fourier spectroscopy.

International Congress of Metrology, $7 \quad-10 \quad$ October, $2013 . \quad$ Paris. 4 pages. http://cfmetrologie.edpsciences.org/articles/metrology/pdf/2013/01/metrology metr2013_10009.pdf

9. L. A. Konopel'ko, V. V. Beloborodov, D. V. Rumyantsev, Ya. K. Chubchenko and V.V.Elizarov. Metrological Problems of Gas Analyzers Based on Wavelength-Scanned Cavity Ring-Down Spectroscopy. Optics and Spectroscopy, 2015, Vol. 118, No. 6, pp. 1017-1022.

10. A. Okeefe and Dag. Deacon, Rev. Sci. Instrum. 59 (12), 2544 (1998). 